\title{
Neurotrophin-3 and FLT3 Tyrosine Kinase Receptor in Perinatal Life
}

\author{
Ariadne Malamitsi-Puchner, Emmanouel Economou, Theodora Boutsikou, \\ Konstantinos E. Nikolaou, and Nikolaos Vrachnis \\ Neonatal Division and Hormonal Laboratory, Second Department of \\ Obstetrics and Gynecology, University of Athens, 11528 Athens, Greece
}

Received 12 October 2004; accepted 15 November 2004

\begin{abstract}
Our aim is to determine - in 30 healthy full-term infants and their mothers_circulating levels of neurotrophin-3 (NT-3) (important for antenatal and postnatal brain development and implicated in the immune response) and FLT3 tyrosine kinase receptor (FLT3) (controlling hematopoiesis and found in the nervous tissue), in the fetal and neonatal life. NT-3 levels, in contrast to FLT3 ones, increased significantly on the fourth postnatal day in relation to the low levels found in the mother, fetus, and day 1 neonate $(P=.03$, respectively). Maternal and umbilical NT3 levels positively correlated with respective FLT3 levels $(P=.003$ and $P=.03)$. Circulating NT-3 levels increased in early neonatal life, possibly due to exposure to various stimuli soon after birth. FLT3 levels do not seem to behave accordingly, although these two substances probably synergize.
\end{abstract}

\section{INTRODUCTION}

Neurotrophin-3 (NT-3) belongs to the neurotrophin family, which includes, among others, the nerve growth factor and the brain-derived neurotrophic factor (BDNF) [1]. Neurotrophins exert antiapoptotic activities in neurons [2] and are implicated in higher neuronal functions [3] and neurotransmitter expression [4]. Therefore, neurotrophins may play important roles in antenatal and postnatal brain development. In addition, neurotrophins are involved in the immune response $[5,6,7,8]$. Moreover, nerve growth factor, BDNF, and NT-3 act on tyrosine kinase $\mathrm{A}, \mathrm{B}$, and $\mathrm{C}$ receptors, respectively. It has recently been reported that in neonatal age circulating neurotrophin levels could reflect the degree of neuronal maturity [1], since, at this age, due to the immature bloodbrain barrier, neurotrophin blood levels may also represent concentrations in the CNS [9].

The FLT3 receptor (FLT3) is a member of the class III receptor tyrosine kinases [10]. Related members of this family of receptors together with their respective ligands have been shown to control numerous distinct stages of hematopoiesis $[11,12]$. Recently, regions of the brain have been shown to harbor neural stem/progenitor cells that retain the capacity to proliferate and to give rise to new

Correspondence and reprint requests to Ariadne MalamitsiPuchner, Neonatal Division and Hormonal Laboratory, Second Department of Obstetrics and Gynecology, University of Athens, 11528 Athens, Greece; amalpu@aretaieio.uoa.gr cells throughout the lifetime of an animal $[10,13]$. Thus, they generate neurons, oligodendrocytes, astrocytes, but also retain the ability to repopulate hematopoietic systems of irradiated animals [14] and to give rise to multiple tissue types when grown in the presence of embryonic stem cells [15]. On the other hand, hematopoietic stem cells have been shown to give rise to neurons, when transplanted into mice $[16,17,18,19]$. In this respect, many studies have confirmed the presence of FLT3 mRNA in nervous tissue $[20,21]$.

This study was based on the hypothesis that a possible interaction between hematopoietic and neuronal activity in the central nervous system, possibly also representing the state of maturity, might be reflected in the periphery. Thus, we aimed to determine circulating levels of NT-3 and FLT3 in full-term neonates and correlate these levels with gestational age, gender, and mode of delivery.

\section{MATERIALS AND METHODS}

The study was approved by the Ethics Committee of our teaching hospital and informed consent was obtained from participating mothers. The study included 30 healthy, infection-free, nonsmoking parturients (mean age: $25.6 \pm 3.4$, range: $20-40$ years) and their healthy neonates appropriate for gestational age and born after single uncomplicated pregnancy and delivery. Apgar scores were $\geq 8$ in the first and fifth minutes. Placentas were in all cases normal in appearance and weight. Complete blood count and C-reactive protein were within normal ranges in all newborns. All infants received breast 
Table 1. Demographic data of participating full-term $(n=30)$ neonates.

\begin{tabular}{c|lc}
\hline \multirow{2}{*}{$\begin{array}{c}\text { Gestational } \\
\text { age (weeks) }\end{array}$} & Mean \pm SD & $39.2 \pm 1.4$ \\
\cline { 2 - 3 } $\begin{array}{c}\text { Gender } \\
\text { (male/female) }\end{array}$ & \multicolumn{2}{|c}{ Range } \\
\hline \multirow{2}{*}{$\begin{array}{c}\text { Mode of } \\
\text { delivery }\end{array}$} & Vaginal & 20 \\
\cline { 2 - 3 } & Elective cesarean section & 10 \\
\hline
\end{tabular}

milk. Developed jaundice required phototherapy treatment in 5 infants. Demographic data of participating neonates are shown in Table 1.

The study assessed circulating levels of NT-3 and FLT3. Thus, blood was taken from (a) the mothers (MS) before delivery (at the first stage of labor, or before receiving anesthesia in cases of elective cesarean section), (b) the doubly clamped umbilical cord (UC) at delivery (UC representing fetal state), and the neonates (c) on the first (N1) and (d) fourth days (N4). The blood was collected in pyrogen-free tubes; following centrifugation the supernatant serum and EDTA plasma were kept frozen at $-80^{\circ} \mathrm{C}$ until assay. NT-3 and FLT3 were determined in serum and EDTA-plasma, respectively, by enzyme immunoassays (R\&D Systems Minneapolis, Minn 55413, catalogue numbers DY 267 and DFK 00, respectively). The minimum detectable concentration, intraassay and interassay coefficients of variations were for NT-3 $1 \mathrm{pg} / \mathrm{mL}, 8.7 \%$ and $14.9 \%$, and for FLT3 less than $7 \mathrm{pg} / \mathrm{mL}$, $2.7 \%$ and $11.1 \%$, respectively.

\section{STATISTICAL ANALYSIS}

Variables were checked for normality of their distribution by Kolmogorov-Smirnov one-sample test. Data not normally distributed were log 10 transformed (NT-3 MS). Unpaired and paired $t$ test was used in the analysis. Furthermore, Pearson correlation coefficient was calculated.

\section{RESULTS}

The circulating NT-3 and FLT3 levels in MS, UC, N1, and $\mathrm{N} 4$ are presented in Table 2. Statistically significant differences were found in NT-3 levels between MS and $\mathrm{N} 4(P=.03)$, UC and N4 $(P=.03)$, and N1 and N4 $(P=.03)$. On the other hand, FLT3 circulating concentrations did not present any difference between the various samples. In addition, MS NT-3, as well as UC NT-3 levels, positively correlated with respective FLT3 levels $(P=.003$, and $P=.03)$. No correlation with gender, gestational age, or mode of delivery was found for either NT-3 or FLT3.

\section{DISCUSSION}

The results of this study indicate that NT-3 serum concentrations rise significantly on the forth day of life, from the low levels encountered in the umbilical cord and on the first postnatal day. Nevertheless, such rise could not be found concerning FLT3.

The significant increase of NT- 3 on the fourth postnatal day may indicate its secretion from the nervous and immune systems of the neonate, as a result of exposure to various stimuli soon after birth. Respectively, in a recent study we demonstrated that the BDNF circulating levels increased significantly in the postnatal period, as compared to the fetal levels [22]. It has been stated that neurotrophins are important for the physiological function of the peripheral as well as the central nervous system, contributing to developmental maturity of the cortex and plasticity of the synapses, leading to the refinement of connections [23]. In addition, previous studies reported that neurotrophins are produced, stored, and released by various immune cells [24], and elevated plasma levels are found in inflammatory, autoimmune, and allergic diseases [8]. Transition of the infant to extrauterine life, where he or she is exposed to a variety of antigenic stimuli [25], including feeding [26], might be responsible for the postnatal significant increase of NT-3. Furthermore, it has been reported that the elevation of neurotrophins might also be a consequence of proinflammatory cytokines [27], the production of which then again is influenced by the former [28]. Accordingly, we have previously demonstrated [29] a significant increase in circulating levels of the proinflammatory cytokines interleukin$1 \beta$, interleukin- 6 , and tumor necrosis factor- $\alpha$ in healthy neonates soon after birth.

Lastly, one should consider a third parameter possibly implicated in the increased postnatal circulating NT-3 levels: its secretion by vascular endothelial cells [30]. The latter multiply and migrate, contributing to the formation of new blood vessels from preexisting ones (angiogenesis) [31], when rapid growth and development is taking place [32], particularly in the third trimester of pregnancy [33], and to a lesser extent in neonatal life.

It has been previously described that many cytokines are shared by the haematopoietic and nervous systems and they exert different functions in different contexts [10]. Nerve growth factor can act as a colony-stimulating factor, as it stimulates immature erythroleukemic cell lines and bone-marrow-derived precursor cells to proliferate [34]. FLT3 is most robustly expressed on differentiated postmitotic neurons, whereas in the hematopoietic system, immature cells preferentially express FLT3 [10]. The lack of increased FLT3 levels in fetal and neonatal samples, according to this study, could possibly be attributed to the fact that examined peripheral blood did not contain immature hematopoietic cells, as neonates were full term and infection free. On the other hand, it has been shown that FLT3 does not play a role as a trophic factor during the early stages of development within the central nervous system [35].

Our finding that MS and UC NT-3 levels, positively correlated with MS and UC FLT3 levels, respectively, could be explained in parallel with the ability of FLT3 
TABLE 2. Circulating neurotrophin-3 (NT-3) and FLT3 tyrosine kinase receptor (FLT3) (mean \pm SD) levels (pg/mL) in mothers (MS), umbilical cords (UC) and neonates on the first (N1) and fourth (N4) days of full-term neonates $(n=30)$.

\begin{tabular}{lcc}
\hline Blood sample & NT-3 & FLT3 \\
\hline MS & $23.6 \pm 6.8$ & $67.9 \pm 5.9$ \\
UC & $27.7 \pm 6.2$ & $55.5 \pm 3.5$ \\
Neonates (first day) & $23.6 \pm 3.2$ & $60.9 \pm 3.4$ \\
Neonates (fourth day) & $43.6 \pm 12.7$ & $59.1 \pm 3.4$ \\
\hline
\end{tabular}

to synergize with NGF, thus to enhance the competence of neurons to respond to neurotrophins [10]. However, a further explanation could take into account the interactions of the nervous and immune systems, particularly under stress situations, as it happens in labor and delivery.

In conclusion, circulating NT-3 levels increase during the early neonatal life. However, circulating FLT3 levels do not seem to behave accordingly, although these two substances probably synergize.

\section{REFERENCES}

[1] Chouthai NS, Sampers J, Desai N, Smith GM. Changes in neurotrophin levels in umbilical cord blood from infants with different gestational ages and clinical conditions. Pediatr Res. 2003;53(6):965969.

[2] Hetman M, Xia Z. Signaling pathways mediating anti-apoptotic action of neurotrophins. Acta Neurobiol Exp (Wars). 2000;60(4):531-545.

[3] Chao MV. Trophic factors: An evolutionary cul-desac or door into higher neuronal function? J Neurosci Res. 2000;59(3):353-355.

[4] Takei N, Nawa H. Roles of neurotrophins on synaptic development and functions in the central nervous system. Hum Cell. 1998;11(3):157-165.

[5] Santambrogio LBM, Benedetti M, Chao MV, et al. Nerve growth factor production by lymphocytes. $J$ Immunol. 1994;153(10):4488-4495.

[6] Xiang Z, Nilsson G. IgE receptor-mediated release of nerve growth factor by mast cells. Clin Exp Allergy. 2000;30(10):1379-1386.

[7] Virchow JC, Julius P, Lommatzsch M, Luttmann W, Renz H, Braun A. Neurotrophins are increased in bronchoalveolar lavage fluid after segmental allergen provocation. Am J Respir Crit Care Med. 1998;158(6):2002-2005.

[8] Noga O, Hanf G, Schaper C, O’Connor A, Kunkel G. The influence of inhalative corticosteroids on circulating nerve growth factor, brain-derived neurotrophic factor and neurotrophin-3 in allergic asthmatics. Clin Exp Allergy. 2001;31(12):1906-1912.

[9] Pollin RA, Fox WW. Fetal and Neonatal Physiology. Philadelphia, Pa: Saunders; 1998:2106-2107.

[10] Brazel CY, Ducceschi MH, Pytowski B, Levison SW. The FLT3 tyrosine kinase receptor inhibits neural stem/progenitor cell proliferation and collaborates with NGF to promote neuronal survival. Mol Cell
Neurosci. 2001;18(4):381-393.

[11] Lyman SD, Jacobsen SEW. c-kit ligand and Flt3 ligand: stem/progenitor cell factors with overlapping yet distinct activities. Blood. 1998;91(4):1101-1134.

[12] Williams DE, Lyman SD. Characterization of the gene-product of the Steel locus. Prog Growth Factor Res. 1991;3(4):235-242.

[13] Scheffler B, Horn M, Blumcke I, et al. Marrowmindedness: a perspective on neuropoiesis. Trends Neurosci. 1999;22(8):348-357.

[14] Bjornson CR, Rietze RL, Reynolds BA, Magli MC, Vescovi AL. Turning brain into blood: a hematopoietic fate adopted by adult neural stem cells in vivo. Science. 1999;283(5401):534-537.

[15] Clarke DL, Johansson CB, Wilbertz J, et al. Generalized potential of adult neural stem cells. Science. 2000;288(5471):1660-1663.

[16] Brazelton TR, Rossi FM, Keshet GI, Blau HM. From marrow to brain: expression of neuronal phenotypes in adult mice. Science. 2000;290(5497):1775-1779.

[17] Mezey E, Chandross KJ, Harta G, Maki RA, Mc Kercher SR. Turning blood into brain: cells bearing neuronal antigens generated in vivo from bone marrow. Science. 2000;290(5497):1779-1782.

[18] Woodbury D, Schwarz EJ, Prockop DJ, Black IB. Adult rat and human bone marrow stromal cells differentiate into neurons. J Neurosci Res. 2000;61(4):364-370.

[19] Sanchez-Ramos J, Song S, Cardozo-Pelaez F, et al. Adult bone marrow stromal cells differentiate into neural cells in vitro. Exp Neurol. 2000;164(2):247256.

[20] Ito A, Hirota S, Kitamura Y, Nomura S. Developmental expression of flt $3 \mathrm{mRNA}$ in the mouse brain. J Mol Neurosci. 1993;4(4):235-243.

[21] deLapeyriere O, Naquet P, Planche J, et al. Expression of Flt3 tyrosine kinase receptor gene in mouse hematopoietic and nervous tissues. Differentiation. 1995;58(5):351-359.

[22] Malamitsi-Puchner A, Economou E, Rigopoulou O, Boutsikou T. Perinatal changes of brain-derived neurotrophic factor in pre- and fullterm neonates. Early Hum Dev. 2004;76(1):17-22.

[23] Lu B, Figurov A. Role of neurotrophins in synapse development and plasticity. Rev Neurosci. 1997;8(1):1-12.

[24] Leon A, Buriani A, Dal Toso R, et al. Mast cells synthesize, store, and release nerve growth factor. Proc 
Natl Acad Sci USA. 1994;91(9):3739-3743.

[25] Bellanti JA, Boner AL, Valleta E. Immunology of the fetus and newborn. In: Klein J, Remington J, eds. Infectious Diseases of the Fetus and Newborn Infant. New York, NY: Saunders; 1989:850-871.

[26] Petschow BW, Talbott RD. Response of bifidobacterium species to growth promoters in human and cow milk. Pediatr Res. 1991;29(2):208-213.

[27] Aloe L, Fiore M, Probert L, Turrini P, Tirassa P. Overexpression of tumour necrosis factor alpha in the brain of transgenic mice differentially alters nerve growth factor levels and choline acetyltransferase activity. Cytokine. 1999;11(1):45-54.

[28] Marshall JS, Gomi K, Blennerhassett MG, Bienenstock J. Nerve growth factor modifies the expression of inflammatory cytokines by mast cells via a prostanoid-dependent mechanism. J Immunol. 1999;162(7):4271-4276.

[29] Protonotariou E, Malamitsi-Puchner A, Giannaki G, Rizos D, Phocas I, Sarandakou A. Patterns of inflammatory cytokine serum concentrations during the perinatal period. Early Hum Dev. 1999;56(1):31-38.

[30] Nakahashi T, Fujimura H, Altar CA, et al. Vascular endothelial cells synthesize and secrete brain-derived neurotrophic factor. FEBS Lett. 2000;470(2):113117.

[31] Folkman J, Klagsbrun M. Angiogenic factors. Science. 1987;235(4787):442-447.

[32] Jackson JR, Seed MP, Kircher CH, Willoughby DA, Winkler JD. The codependence of angiogenesis and chronic inflammation. FASEB J. 1997;11(6):457465.

[33] Beck L Jr, D’Amore PA. Vascular development: cellular and molecular regulation. FASEB $J$. 1997;11(5):365-373.

[34] Chevalier S, Praloran V, Smith C, et al. Expression and functionality of the trkA proto-oncogene product/NGF receptor in undifferentiated hematopoietic cells. Blood. 1994;83(6):1479-1485.

[35] Mackarehtschian K, Hardin JD, Moore KA, Boast S, Goff SP, Lemischka IR. Targeted disruption of the flk2/flt3 gene leads to deficiencies in primitive hematopoietic progenitors. Immunity. 1995;3(1):147-161. 


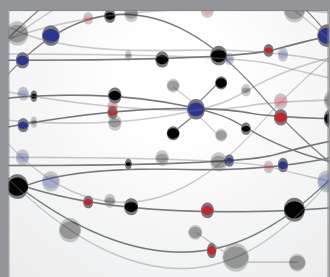

The Scientific World Journal
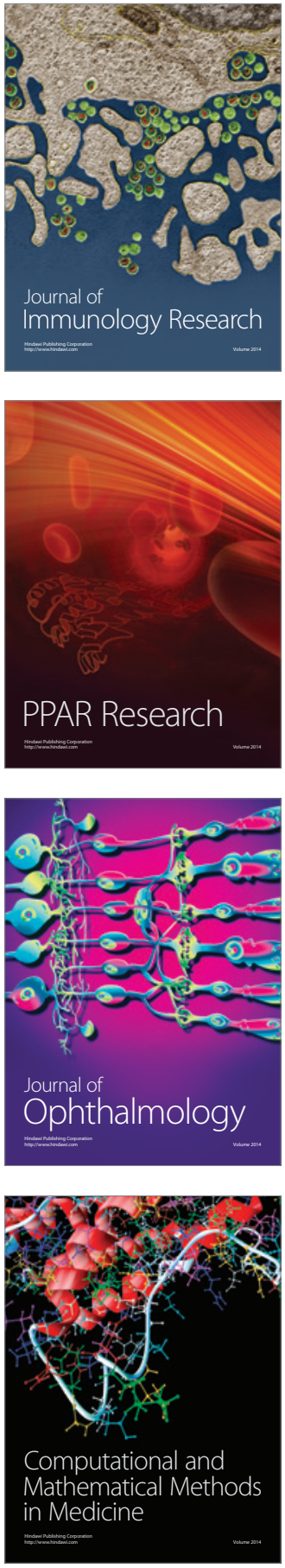

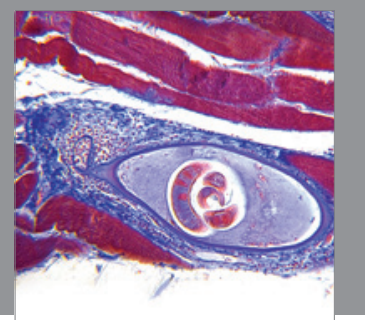

Gastroenterology

Research and Practice
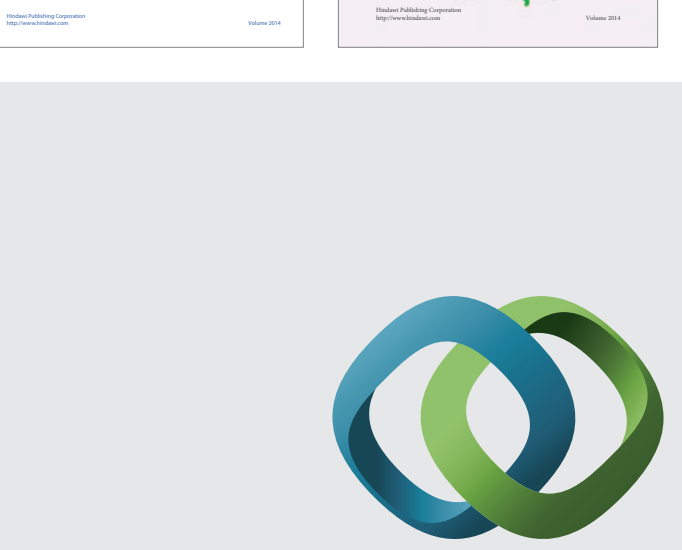

\section{Hindawi}

Submit your manuscripts at

http://www.hindawi.com
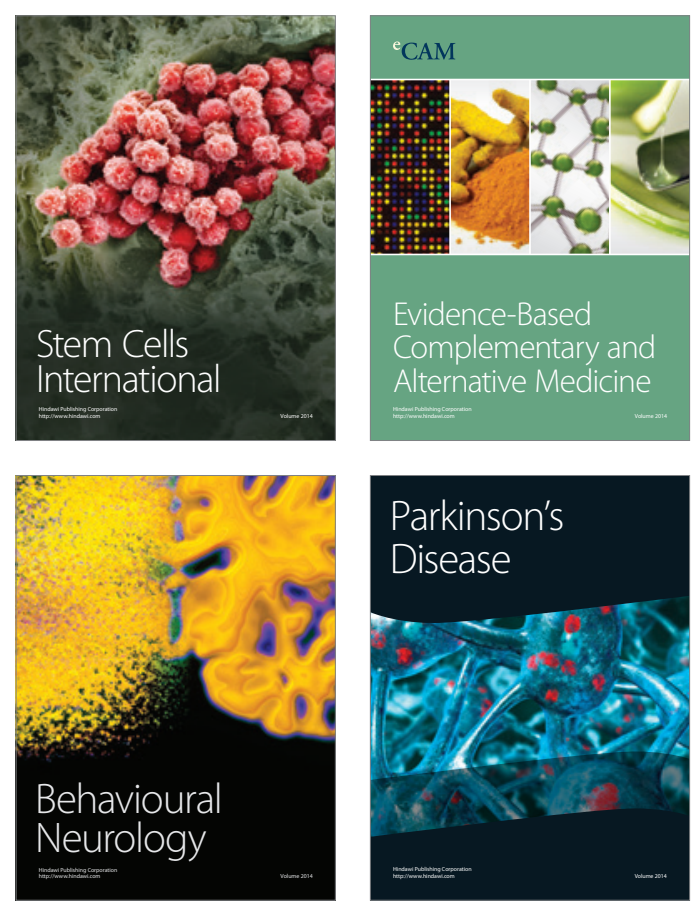

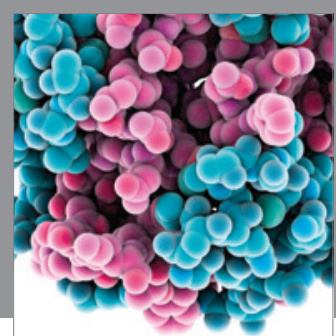

Journal of
Diabetes Research

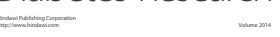

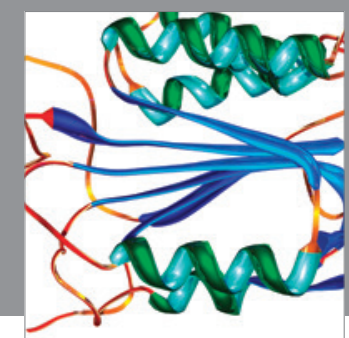

Disease Markers
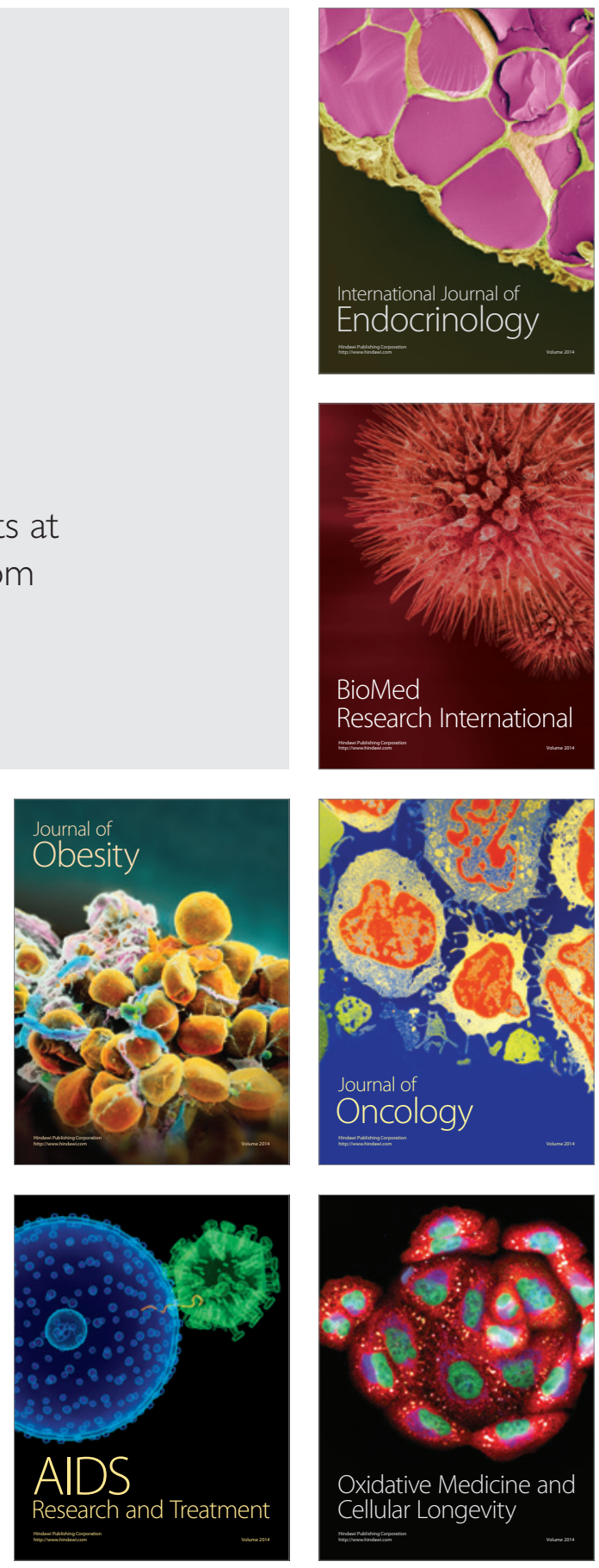